\title{
Psychological Effects Related to Accident among Victims
}

\author{
Mugahed Al-Khader'1, Fahad Mohammed Ali Al Mirdef ${ }^{2}$ \\ ${ }^{1}$ Assistant Prof. Medical Surgical Nursing, Faculty of Nursing, Najran University, Saudi Arabia \\ ${ }^{2}$ Faculty of Nursing, Najran University, Saudi Arabia
}

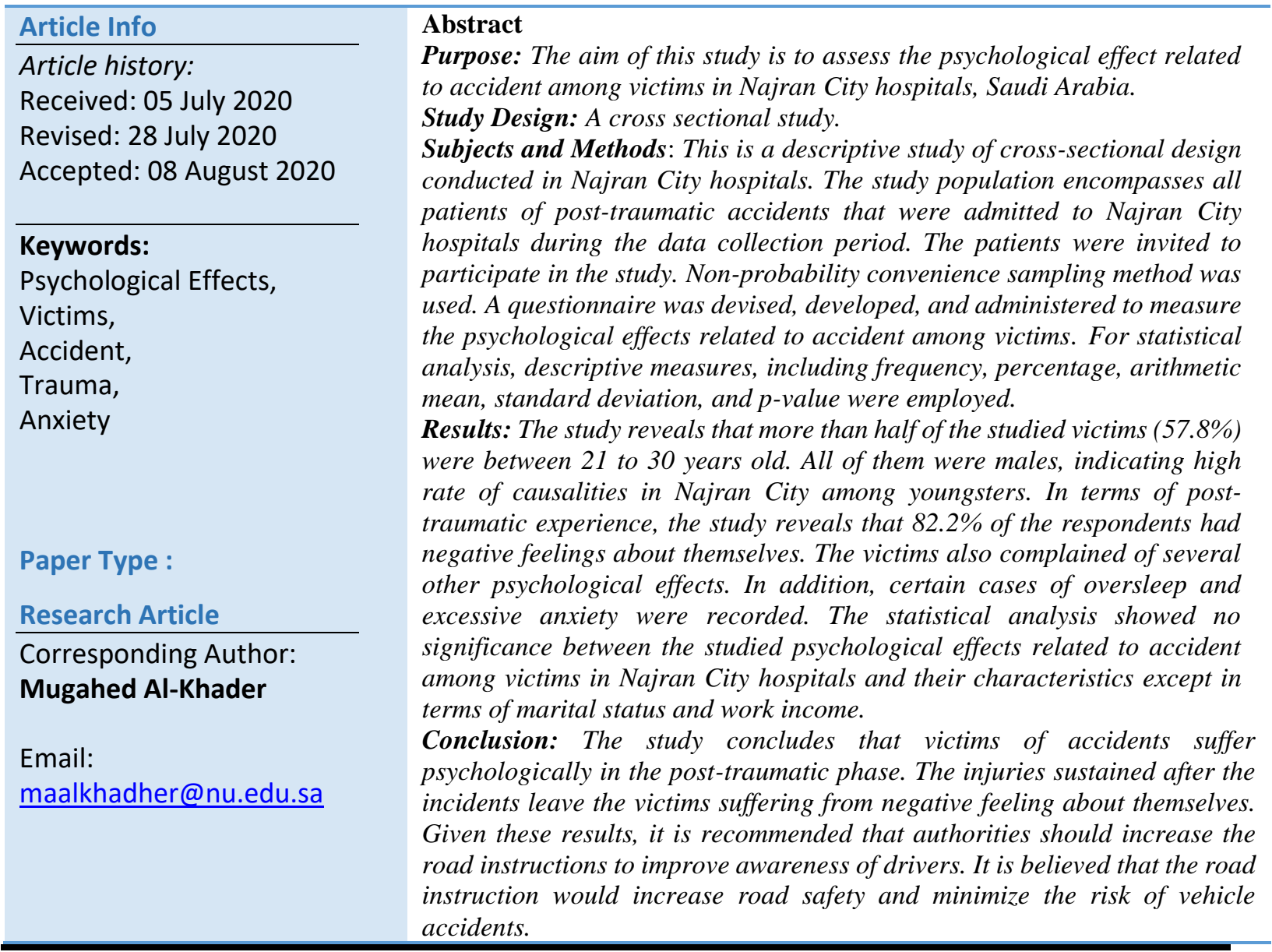

\section{Introduction}

Psychological distress is defined as an unpleasant condition that can negatively influence daily functioning, including a range of symptoms commonly believed to be troubling and disturbing, such as elevated anxiety and depressive mood (Craig et al., 2016). Psychological trauma can leave the individual struggling with upsetting emotions, memories, and anxiety that does not go away easily. It can also leave one feeling numb, disconnected, and unable to trust other people. When bad things happen, it can take a while to get over the pain and feel safe again. But with certain self-help strategies and support, the patient can speed up recovery. Whether the trauma happened years ago or yesterday, the victim can make healing changes and move on with his/her life (Robinson, et al., 2019). 
The most common symptoms of psychological trauma are shock, denial, or disbelief confusion, difficulty concentrating, anger, irritability, mood swings, anxiety, fear, guilt, shame, and self-blame (Robinson, et al., 2019). Psychological difficulties after a road traffic accident can adversely affect an individual's quality of life at least as much as a physical injury. They can relate directly to emotional trauma and associated restriction, or to the consequences of physical injury. Phobic travel anxiety, post trauma reactions, and depression are all frequently experienced, though fortunately most people suffer only transient physical injuries and little persistent psychological adverse reaction (Simon, 2003).

Injuries associated with road crashes are a primary cause of morbidity and mortality in developed and developing countries (Craig et al., 2016). It has been estimated by the World Health Organization that between 20 and 50 million people are injured as a result of road traffic accidents (RTAs) around the world each year. RTAs have been argued to be the leading cause of post-traumatic stress disorder. Despite improved car safety, the present study confirms that the psychological effects of road traffic are still an issue post-traumatic stress disorder (PTSD) (Cartwright, 2018).

Many children and adolescents are exposed to traumatic experiences every year. Over $30 \%$ of children develop a clinical syndrome with emotional, behavioural, cognitive, social, and physical symptoms called post-traumatic stress disorder (PTSD). Road traffic accidents (RTAs) are the main cause of morbidity and mortality in ages 0-19 in industrialized countries. For instance, in Greece, 30,000 individuals are injured and 2000 die in RTAs. Every year, 40\% of them are between 15 and 34 years old (Charitaki et al., 2017). Severe post-traumatic stress reaction was associated with increased rates of anxiety and depression and decreased quality of life.

In relation to all this, the present study aims to determine the types of psychological effect caused due to accidents in Najran city, Saudi Arabia. The aim is also to evaluate the current situation and develop new therapeutic interventions which might reduce the impact of psychological traumatic complications. The overall aim is to improve the quality of life of those who survive psychological effects related to accidents (Azoulay, et al., 2003).

\section{Methodology and Procedures}

This study used a cross-sectional design and it was conducted in two main hospitals in Najran City; King Khaled Hospital and Modern Najran Hospital. All the patients of posttraumatic accident and admitted to Najran city hospitals during the data collection period were invited to participate in the study. Non-probability convenience sampling method was used in this study. The study inclusion criteria are all the patients of post-traumatic accidents that are admitted to Najran city hospitals, all patients with voluntary participation in this study, and age group ranges from 15 to 60 years old. All patients not fulfilling the above inclusion criteria were excluded. The study was conducted in two months in 2020.

A questionnaire was developed and administered to collect data. In addition to this tool, a direct interview was conducted with the patients, collecting demographic data as well as recounting accidents psychological experience. A pilot study was done in the study setting on 
$10 \%$ of the study sample to identify practical or local problems that might potentially affect the research process. The researchers filled the questionnaire to obtain validity and reliability of the questionnaire. For the pilot study, 5 participants were selected from Najran City hospitals, and the result was satisfactory.

A packaged computer analysis program, statistical package for the social science (SPSS Version (20) was used for statistical analysis of obtained data. Descriptive measures, including frequency, percentage, arithmetic mean and standard deviation, p-value, were assessed by the true parameters. More importantly, approval was obtained from the ethics committee of Faculty of Nursing-Najran University prior to carrying out this study. All the participants also had the right to refuse to take part or to withdraw from the study.

\section{Results and Discussion}

The analysis of the data obtained is presented in the following tables. The presentation of data is presented in two parts. The first part presents the data relevant to the victims' demographic characteristics, while the second part presents the data obtained about the physiological effects. Moreover, the third part of the analysis examines the relationship between the total scores of the studied victims' psychological effect related to accident in Najran City Hospitals and their characteristics.

\section{Part I: Characteristics of the Studied Victims}

Table 1: Number and Percentage Distribution of the Studied Victims Regarding their Characteristics $(n=\mathbf{4 5})$.

\begin{tabular}{|l|c|c|}
\hline Items & Frequency & Percentage \\
\hline Age / year & 12 & 26.7 \\
\hline$<20$ & $\mathbf{2 6}$ & $\mathbf{5 7 . 8}$ \\
\hline $21-30$ & 5 & 11.1 \\
\hline $31-40$ & 2 & 4.4 \\
\hline $41-50$ & 0 & 0 \\
\hline 51 and above & 45 & $\mathbf{1 0 0}$ \\
\hline Gender & 22 & $\mathbf{4 8 . 9}$ \\
\hline Male & 22 & $\mathbf{4 8 . 9}$ \\
\hline Marital Status & 0 & $\mathbf{0}$ \\
\hline Single & 0 & $\mathbf{0}$ \\
\hline Married & 1 & $\mathbf{2 . 2}$ \\
\hline Divorced & 2 & 4.4 \\
\hline Widowed & 7 & 15.6 \\
\hline Separated & 6 & 13.3 \\
\hline Level of Education & $\mathbf{4 8 . 9}$ \\
\hline Illiterate & \multicolumn{2}{|l|}{} \\
\hline Primary & \multicolumn{2}{|l|}{} \\
\hline Secondary & \multicolumn{2}{|l|}{} \\
\hline High School & \multicolumn{2}{|l|}{} \\
\hline 2709-0159 (Print) & \multicolumn{2}{|l|}{} \\
\hline
\end{tabular}

ISSN: 2709-0159 (Print)

Copyright (C) 2020, Journal of Scientific Research in Medical and Biological Sciences (JSRMBS), Under the license CC BY- 4.0 


\begin{tabular}{|c|c|c|}
\hline University & 8 & 17.8 \\
\hline \multicolumn{3}{|l|}{ Work Status } \\
\hline Employed & 38 & 84.5 \\
\hline Self-employed & 6 & 13 \\
\hline Jobless/Farmer/Worker & 0 & 0 \\
\hline University Student & 1 & 2.5 \\
\hline \multicolumn{3}{|l|}{ Work Income } \\
\hline Poor & 9 & 20 \\
\hline Moderate & 24 & 53.3 \\
\hline Good & 5 & 11.1 \\
\hline Very Good & 7 & 15.6 \\
\hline \multicolumn{3}{|l|}{ Type of Injury } \\
\hline Head and brain injuries & 7 & 15.6 \\
\hline Chest and Abdominal injuries & 0 & 0 \\
\hline Fractures and bone injuries & 35 & 77.7 \\
\hline Spinal cord injury & 3 & 6.7 \\
\hline \multicolumn{3}{|l|}{ Cause of Injury } \\
\hline Road Traffic Accident & 39 & 86.7 \\
\hline Fall & 4 & 8.9 \\
\hline Gunshot & 1 & 2.2 \\
\hline Burn & 1 & 2.2 \\
\hline \multicolumn{3}{|l|}{ Time of the Accident } \\
\hline Less than one week & 15 & 33.4 \\
\hline One week less than one month & 20 & 44.4 \\
\hline One month less than one year & 10 & 22.2 \\
\hline More than one year & 0 & 0 \\
\hline \multicolumn{3}{|c|}{ Psychological Effect after the Accident } \\
\hline Depression & 7 & 15.6 \\
\hline Hopeless & 6 & 13.3 \\
\hline Anxiety & 24 & 53.3 \\
\hline Loneliness & 8 & 17.8 \\
\hline
\end{tabular}

\section{Source: Authors}

Table (1) revealed that more than half of the studied victims (57.8\%) are between 21 to 30 years old. As indicated above, all of them (100\%) were males. More importantly, less than $48.9 \%$ of them are single, reflecting that most of the accidents in Nijran city occur among young men. In addition, $48.9 \%$ of the victims had high school education and more than three quarters of the participants (84.5\%) were employed. Assessing the type of trauma, table 1 above indicates that $77.7 \%$ of the victims had fractures and bone injuries. Moreover, more than three quarters of them (86.7\%) reported that they had road traffic accident. Apparently, road accident remains the main cause of injury for the victims admitted in Nijran hospitals. The accidents are frequent in Nijran city as most of the victims reported their accidents happened between one week and less than one month from meeting them in the hospital. In terms of psychological effect, the participants rated anxiety as the most frequent feeling after the accident. As shown in table 1, the majority of the participant $53.3 \%$ reported anxiety as a post-trauma effect, and the second most rated effect is loneliness, scoring $17 \%$. 


\section{Part II: Psychological Effect Related to Accident among Victims in Najran City Hospitals}

Table 2: Number and percentage distribution of the studied victims' psychological effect related to accident among victims in Najran City Hospitals $(n=\mathbf{4 5})$.

\begin{tabular}{|c|c|c|c|c|}
\hline Items & \multicolumn{2}{|c|}{ Yes } & \multicolumn{2}{c|}{ No } \\
\cline { 2 - 5 } & Frequency & \% & Frequency & \% \\
\hline Did you have disability before this accident? & 6 & 13.3 & 39 & $\mathbf{8 6 . 7}$ \\
\hline $\begin{array}{c}\text { Were you exposed to previous motor vehicle } \\
\text { accident before this accident? }\end{array}$ & 5 & 11.1 & 40 & $\mathbf{8 8 . 9}$ \\
\hline $\begin{array}{c}\text { Were you exposed to serious trauma before } \\
\text { this accident? }\end{array}$ & 7 & 15.6 & 38 & $\mathbf{8 4 . 4}$ \\
\hline $\begin{array}{c}\text { Were you suffering from any physical } \\
\text { chronic disease before this accident? }\end{array}$ & 7 & 15.6 & 38 & $\mathbf{8 4 . 4}$ \\
\hline $\begin{array}{c}\text { Are you feeling any depression and } \\
\text { hopelessness after this accident? }\end{array}$ & 30 & 66.7 & 15 & 33.3 \\
\hline $\begin{array}{c}\text { Are you having a little interest or pleasure in } \\
\text { doing things after this accident? }\end{array}$ & 29 & 64.4 & 16 & 35.6 \\
\hline $\begin{array}{c}\text { Are you having a feeling to stay asleep after } \\
\text { this accident? }\end{array}$ & 36 & $\mathbf{8 0}$ & 9 & 20 \\
\hline $\begin{array}{c}\text { Do you feel tired or having little energy } \\
\text { after this accident? }\end{array}$ & 20 & 44.4 & 25 & 55.6 \\
\hline $\begin{array}{c}\text { Are you suffering from poor appetite after } \\
\text { this accident? }\end{array}$ & 13 & 28.9 & 32 & 71.1 \\
\hline $\begin{array}{c}\text { Do you feel bad about yourself after this } \\
\text { accident? }\end{array}$ & 8 & 17.8 & 37 & $\mathbf{8 2 . 2}$ \\
\hline $\begin{array}{c}\text { Are you having a trouble to concentrate } \\
\text { after this accident? }\end{array}$ & 19 & 42.2 & 26 & 57.8 \\
\hline $\begin{array}{c}\text { Are you having a problem in moving or } \\
\text { speaking slowly after this accident? }\end{array}$ & 36 & $\mathbf{8 0}$ & 9 & 20 \\
\hline $\begin{array}{c}\text { Are you having thoughts of being better } \\
\text { after this accident? }\end{array}$ & 12 & 26.7 & 33 & 73.3 \\
\hline $\begin{array}{c}\text { Are you becoming more anxious about } \\
\text { driving vehicles after this accident? }\end{array}$ & 22 & 48.9 & 23 & 51.1 \\
\hline
\end{tabular}

\section{Source: Authors}

Regarding studied psychological effect related to accident among victims in Najran City Hospitals, Table (2) presents the percentages and frequencies obtained from the participants. As it is clearly presented, more than three quarters of the participants $(86.7 \%, 88.9 \%, 84.4 \%$, and $84.4 \%)$ had no disability before their accidents, not exposed to previous motor vehicle accident before this accident, not exposed to serious trauma before this accident and do not have physical chronic disease before this accident, respectively. After the accidents, the participants' responses varied, reporting numerous psychological effects. The accidents resulted in $80 \%$ of the victims suffering from sleep disorders. Furthermore, $80 \%$ of the participants indicated physical disability, having a problem in moving or speaking slowly after the accidents. Also, more than 
three quarters of them (82.2\%) had a bad feeling about themselves after the accident. This type of feeling is a resultant of guilt and self-blame.

Figure 1: Percentage distribution of total score of psychological effect related to accident among victims in Najran City Hospitals ( $\mathrm{n}=45)$.

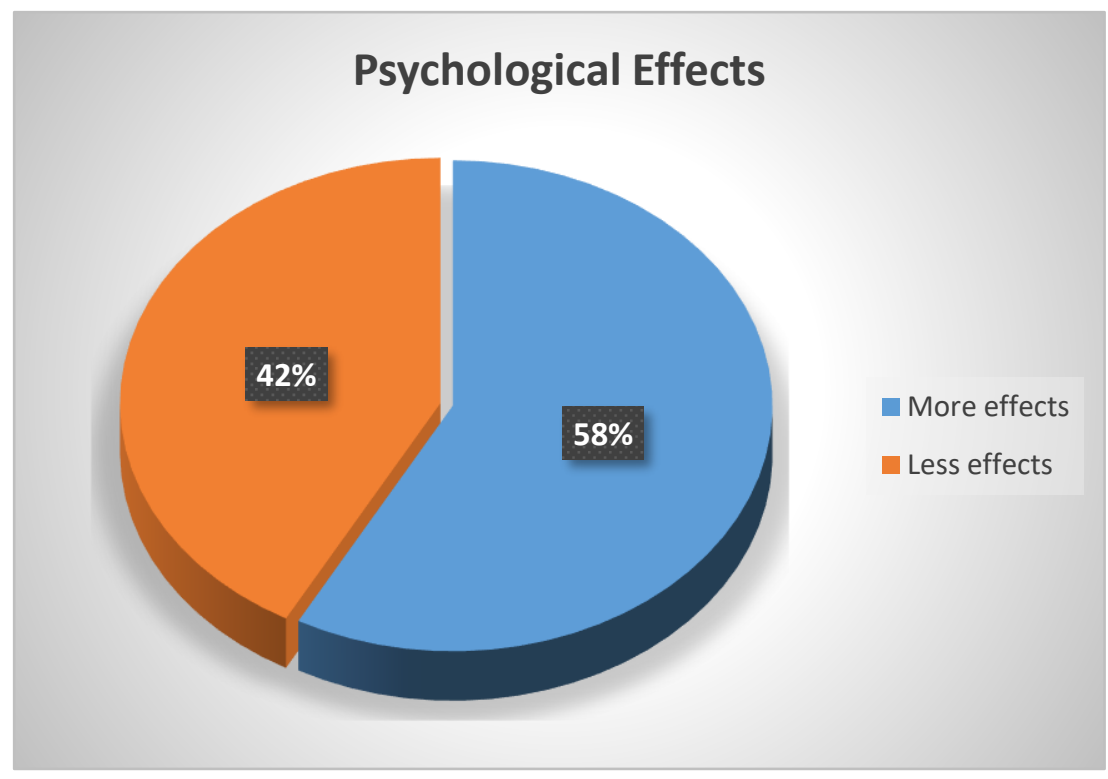

Figure 1: Percentage distribution of total score of psychological effect related to accident among victims in Najran City Hospitals ( $n=45)$.

Source: Authors

In Figure (1), it is obvious that more than half of the studied victims (58\%) had high level of psychological effects, while less than half of them (42\%) had low level of psychological effects. The figure indicates that psychological effects are moderate among the vehicle accident victims in Nijran city.

Part III: Relation between total scores of the studied victims' Psychological effect related to accident in Najran City Hospitals and their characteristics

Table 3: Relation between total scores of the studied victims' Psychological effect related to accident in Najran City Hospitals and their characteristics (table 3). $(n=\mathbf{4 5})$.

\begin{tabular}{|c|c|c|c|c|c|c|}
\hline \multirow{2}{*}{\multicolumn{2}{|c|}{ Variables }} & \multicolumn{2}{|c|}{ More Effects } & \multicolumn{2}{|c|}{ Less Effects } & \multirow{2}{*}{ P. Values } \\
\hline & & \multirow{2}{*}{$\begin{array}{c}\text { Frequency } \\
12\end{array}$} & \multirow{2}{*}{$\frac{\%}{26.7}$} & \multirow{2}{*}{$\begin{array}{c}\text { Frequency } \\
<20\end{array}$} & \multirow{2}{*}{$\begin{array}{l}\% \\
12\end{array}$} & \\
\hline \multirow{4}{*}{$\begin{array}{l}\text { Age in } \\
\text { years }\end{array}$} & $<20$ & & & & & \multirow{4}{*}{ Sig.:0.137 NS } \\
\hline & $21-30$ & 26 & 57.8 & $21-30$ & 26 & \\
\hline & $31-40$ & 5 & 11.1 & $31-40$ & 5 & \\
\hline & $41-50$ & 2 & 4.4 & $41-50$ & 2 & \\
\hline Gender & Male & 26 & 57.7 & 19 & 42.2 & NS \\
\hline \multirow{3}{*}{$\begin{array}{c}\text { Marital } \\
\text { Status }\end{array}$} & Single & 14 & 31.1 & 8 & 17.7 & \multirow{3}{*}{$\begin{array}{c}\text { Sig.: } \\
0.001 \\
\text { NS }\end{array}$} \\
\hline & Married & 11 & 24.4 & 11 & 24.4 & \\
\hline & Separated & 1 & 2.2 & 0 & 0 & \\
\hline
\end{tabular}

ISSN: 2709-0159 (Print)

Copyright (C 2020, Journal of Scientific Research in Medical and Biological Sciences (JSRMBS), Under the license CC BY- 4.0 


\begin{tabular}{|c|c|c|c|c|c|c|}
\hline \multirow{4}{*}{$\begin{array}{c}\text { Educational } \\
\text { level }\end{array}$} & Illiterate & 2 & 4.4 & 0 & 0 & \\
\cline { 2 - 6 } & Primary & 4 & 8.8 & 3 & 6.6 & \multirow{3}{*}{ Sig. : } \\
\cline { 2 - 6 } & Secondary & 5 & 11.1 & 1 & 2.2 & 0.191 NS \\
\cline { 2 - 6 } & High School & 11 & $\mathbf{2 4 . 4}$ & 11 & $\mathbf{2 4 . 4}$ & \\
\cline { 2 - 6 } & University & 4 & 8.8 & 4 & 8.8 & \\
\hline \multirow{3}{*}{$\begin{array}{l}\text { Work } \\
\text { Status }\end{array}$} & Employed & 21 & $\mathbf{4 6 . 6}$ & 17 & 37.7 & \multirow{2}{*}{ Sig.: } \\
\cline { 2 - 6 } & Self-employed & 4 & 8.8 & 2 & 4.4 & 0.129 NS \\
\cline { 2 - 6 } $\begin{array}{c}\text { Work } \\
\text { Income }\end{array}$ & University Student & 1 & 2.2 & 0 & 0 & \\
\cline { 2 - 6 } & Poor & 5 & 11.1 & 4 & 8.8 & \\
\cline { 2 - 6 } & Moderate & 13 & $\mathbf{2 8 . 8}$ & 11 & 24.4 & \multirow{2}{*}{ Sig.: $0.011 \mathrm{~S}$} \\
\cline { 2 - 6 } & Good & 5 & 11.1 & 0 & 0 & \\
\hline
\end{tabular}

\section{P-value $\leq 0.05 *$ statistically significance}

\section{Source: Authors}

Table (3) is a presentation of the data regarding relation between the studied psychological effect related to accident among victims in Najran City Hospitals and their characteristics. This table shows that more than half of the participants in the study (57.7\%) were males and had high level of psychological effect. As the analysis shows, more than one quarter of them $(31.1 \%)$ are aged between 21 to 30 years old. This age category had low level of psychological effect. On the contrary, $31.1 \%$ and $28.8 \%$ were single and had moderate work income reported that they had high level of psychological effect. Moreover, nearly half of the victims (46.6\%) were employed and the table above indicates they had high level of psychological effect. So, there were no statistically significant relation between the studied psychological effect related to accident among victims in Najran City Hospitals and their characteristics $(\mathrm{P}>0.05)$ except marital status and work income $(P<0.05)$.

The objective of this study was to measure the psychological effects related to accident among victims in Najran City Hospitals. The results of this study are based on the primary data gathered from 45 patients. All the participants in the current study were selected by employing a convenience sampling method. This section presents the major findings of the study and discusses them in relation to similar studies conducted by other researchers, supporting the findings about psychological effect related to accident among victims in Najran City Hospitals.

In this study, the results showed that more than half of the studied victims (57.8\%) were between 21 to 30 years old. All of these vehicle accidents victims were males. This finding of the present study is in line with a study conducted by Cartwright, A. (2018). that concluded that the majority of the studied cases were male, because they were more likely to be motor vehicle drivers and hence more prone to injury compared to the females. In another study by Guest, et al., (2017), it is found out that the majority of victims suffered from post-traumatic stress. This is also in line with the current study in which it is revealed that more than half of victims $(53.3 \%)$ had anxiety after accident.

In addition, the current study reveals that more than three quarters of the studied victims $(82.2 \%)$ had a bad feeling about themselves after the accidents. This finding is in agreement with the study carried out by Bampi, et al., (2008), that showed that the majority of participants had low self-steam after motor car accident. This feeling comes out as a result of guilt and selfblame, leaving the individual in destabilized psychological state.

ISSN: 2709-0159 (Print)

Copyright (C 2020, Journal of Scientific Research in Medical and Biological Sciences (JSRMBS), Under the license CC BY- 4.0 
In the current study, it is showed that more than two thirds of victims $(77.7 \%)$ had fractures and bone injuries. This finding is also previously reported in a study by DeNicola, et al., (2016) in which the majority of participants were exposed to bone injuries after motor car accident. Regarding psychological effect related to accident among victims, the findings of the current study indicate that more than half of the victims $(57.7 \%)$ had high level of psychological effect. These results also are similar to the findings of the study conducted by Whelan, et al., (2009) in which the results indicated that the patients after motor car accident had a high frequency of post-injury psychiatric disorders such as anxiety, depression and posttraumatic stress.

\section{Conclusion and Suggestion}

All of the studied participants involved in the study were male and more than three quarters of them were employed. While more than two thirds of them had fractures and bone injuries, more than three quarters of them had road traffic accidents. The study concludes that more than half of the victims admitted to Nijran hospitals during the study period had anxiety after accident. Regarding studied psychological effect related to accident among victims, the current study reveals that more than three quarters of the participants had feeling to staying asleep after their accidents. They also reported a difficulty in moving or speaking after the accident. The study also points out that a quite significant percentage of the vehicle- accident victims, more than three quarters of them, had a decreasing self-esteem after their accidents.

Regarding the relationship between the studied psychological effect related to accident among victims in Najran City Hospitals and their characteristics, the current study showed that there were no statistically significant relationship between the studied psychological effects related to accident among victims in Najran City Hospitals and their characteristics except in terms of marital status and work income.

\section{Conflict of Interest}

The authors of the article declare no conflict of interest.

\section{Funding:}

The authors received no funding for conducting this study.

\section{References}

Azoulay, E., Pochard, F., Kentish-Barnes, N., Chevret, S., Aboab, J., Adrie, C., \& Fassier, T. (2005). Risk of post-traumatic stress symptoms in family members of intensive care unit patients. American journal of respiratory and critical care medicine, 171(9), 987994. doi: 10.1164/rccm.200409-1295OC.

Bampi, L. N. D. S., Guilhem, D., \& Lima, D. D. (2008). Qualidade de vida em pessoas com lesão medular traumática: um estudo com o WHOQOL-bref. Revista Brasileira de Epidemiologia, 11, 67-77.

Cartwright, A. (2018). The psychological effects of road traffic accidents (RTAs): an 
exploration of a United Kingdom medico-legal examiner's career of RTA assessments. Psychiatry, psychology and law, 25(2), 303-324. doi: 10.1080/13218719.2017.1396864.

Charitaki, S., Pervanidou, P., Tsiantis, J., Chrousos, G., \& Kolaitis, G. (2017). Post-traumatic stress reactions in young victims of road traffic accidents. European Journal of Psychotraumatology, 8(sup4), 1351163. doi:10.1080/20008198.2017.1351163.

Craig, A., Tran, Y., Guest, R., Gopinath, B., Jagnoor, J., Bryant, R. A., \& Cameron, I. (2016). Psychological impact of injuries sustained in motor vehicle crashes: systematic review and meta-analysis. BMJ open, 6(9), pp. 1- 13. doi: 10.1136/bmjopen-2016011993.

DeNicola, E., Aburizaize, O. S., Siddique, A., Khwaja, H., \& Carpenter, D. O. (2016).

Road traffic injury as a major public health issue in the Kingdom of Saudi Arabia: A Review. Frontiers in public health, 4, 215.

Easton, S. (2003). Psychological effects of road traffic accidents: issues, research and complexities for expert reports. Medico-Legal Journal, 71(3), 130-137.

Robinson, L. Smith, M., \& Segal J. (2019) Emotional and Psychological Trauma. Retrieved August 08, 2020, from https://www.helpguide.org/articles/ptsd-trauma/coping-withemotional-and-psychological-trauma.htm

Whelan-Goodinson, R., Ponsford, J., Johnston, L., \& Grant, F. (2009). Psychiatric disorders following traumatic brain injury: their nature and frequency. The Journal of Head Trauma Rehabilitation, 24(5), 324-332. 